\title{
Social Capital and Secondary Schooling: Interurban Differences in American Teenage Enrollment Rates in 1950
}

\author{
JOHN L. RURY \\ University of Kansas
}

This article considers the influence of social capital on secondary enrollments in American cities in 1950. Data from the U.S. census are utilized to analyze enrollment rates across metropolitan areas with populations greater than 500,000 . The effects of adult education levels and poverty rates were linked to social capital; employment patterns and the size of various ethnic groups also affected enrollment levels. Overall, trends were similar to those observed in studies of earlier periods, but this article identifies certain urban milieus where community values may have encouraged high school attendance, representing a departure from earlier patterns. Characteristics of particular communities and forms of social capital related to school attendance are discussed.

Much attention has been given to the concept of "social capital" in recent years, particularly with regard to education. As defined by James Coleman, it represents the power of relationships to affect educational and social change, a resource both for individuals and communities. As Coleman noted, however, it is difficult to observe social capital directly, as "it inheres in the structure of relations, between actors and among actors," patterns of association that shape interaction and influence behavior $(1988$, p. 98). As such, it is manifest in values that are shared within groups and across social networks and can be seen in activities observed across communities and even nations. While much research on social capital and education has focused parental and neighborhood influences on achievement, some studies have considered these questions at a higher level of aggregation, using historical data to address why certain communities or groups have succeeded in education and social development (Rotberg 2001). This article contributes to the latter line of inquiry, investigating the determinants of high school enrollment in American cities in the mid-twentieth century. Social capital appears to have been an important factor in the profile of urban secondary attainment; as a characteristic of 


\section{Social Capital and Secondary Schooling}

communities and social groups, it may have had a palpable effect on education.'

Researchers have offered many explanations of why teenage school attendance varied in the past, but few have considered the possible effects of social capital. One interpretive framework has been largely economic, focusing on the opportunity costs of extended school attendance. These studies suggested that working class youth, both male and female, left school to take jobs in factories, especially if they lived in industrial areas and their families needed additional income (Katz and Davey 1978). Other explanations dealt with access to schools, especially in the South and other areas where districts lacked resources and could not offer extensive secondary programs (Walters and James 1992). Yet other researchers have framed the question in cultural terms. Children from various immigrant groups attended at differing rates, exhibiting what historians have interpreted as differing preferences regarding education (Perlmann 1988). For the most part, however, this literature predated Coleman's identification of social capital as a factor in educational attainment. It is possible, then, that it contributed to the differences attributed to these various elements, depending on the nature of relationships that affected decisions about schooling.

As a matter of empirical analysis, this article examines factors that induced or impeded high school enrollment in American cities in the mid-twentieth century, with attention to identifying the influence of social capital. This question is addressed with the use of city-level data on the enrollment of 16- and 17-year-old urbanites taken from published 1950 U.S. census volumes. In examining interurban variations in teenage school enrollment, linked with a wide range of other city characteristics, it is possible to identify the conditions under which high schools flourished and those that contributed to large numbers of what later would be described as "dropouts" (Dorn 1996). In other words, the article asks why some cities provided more encouraging contexts than others for youth to remain in school, and one factor that may have affected this was the local stock of relevant social capital.

School Enrollment and Social Capital: Interpretive Issues

As noted earlier, many researchers have explored the question of school participation for teenagers in the past, and much of this scholarship has focused

JOHN L. RURY is professor and chair, Department of Teaching and Leadership, University of Kansas. His books include Education and Social Change (2002), Education and Women's Work (1991), and Seeds of Crisis: Public Schooling in Milwaukee since 1920 (1993). 
on schools in cities. In general, this body of research has found that enrollment patterns were affected by several factors, but one especially important consideration was the nature of local labor markets. Early studies emphasized the negative association of industrial employment and school enrollment, particularly in the nineteenth and early twentieth centuries. For instance, Pamela Walters and her various collaborators found that employment variables exerted strong effects on enrollment levels (Walters and O'Connell 1988). Utilizing state and national level data sets, they established that the expansion of enrollments at both the secondary and tertiary levels was influenced by the changing occupational structure. In particular, these studies have suggested that employment in professional and technical jobs proved an inducement to postsecondary enrollments in the postwar period and that industrial jobs may have inhibited high school attendance, at least through the 1940s. Similar patterns have been evident in other studies. During the nineteenth century many teenagers left school in order to take factory jobs, males and females alike. Places with relatively high employment in white-collar jobs, calling for school credentials, exhibited higher levels of school enrollment. In short, there was a broad correspondence between attendance rates and the dictates of the local labor market (Fuller 1983; Greene and Jacobs 1992; Rury 1984)."

By and large, however, these studies did not take account of certain other factors that may have influenced enrollment rates in the same way. One of these is the level of education in the adult population. High overall attainment may have been associated with white-collar employment, exerting an independent effect on high school enrollment that could also be linked to social capital. A positive correlation between levels of adult attainment and high school enrollment can be interpreted as prima facie evidence of social capital, assuming that the behavior of students is consistent with the experience (and by extension the valucs) of their parents and other adults in the community. As Coleman has suggested, social capital contributes to the transmission of values and behavior from one generation to the next. Indeed, without it, he suggests that it is doubtful that such transfers would occur: "Human capital may be irrelevant to outcomes for children if parents are not an important part of their children's lives. . . . If the human capital possessed by parents is not complemented by social capital embedded in family relations, it is irrelevant to the child's educational growth that the parent has a great deal, or a small amount, of social capital" (Coleman 1988, p. 110). In the absence of sturdy and positive relationships between parents and children, supported by appropriate social networks, adult attitudes toward education would have been less likely to influence the behavior of youth. A strong correlation between parental (adult) and youth behavior in this regard, in settings where robust networks are probable, thus can be interpreted as representing the influence of social capital. 


\section{Social Capital and Secondary Schooling}

Another factor that earlier studies often did not consider is economic status, as reflected in wealth and income. This partly has been a consequence of data limitations, particularly in the U.S. census manuscript schedules that provided much of the information for these studies (Kaestle and Vinovskis 1980). Some researchers have argued that disparities in this dimension of social status have served to fragment communities, undermining the possibility of cohesive networks that contribute to social capital formation (Goldin and Katz 1999). Simply put, people from different economic status groups usually do not associate with one another in ways that build lasting relationships and reciprocal trust. Of course, many other issues are associated with economic inequality. Poor people historically have been less engaged with schools and a number of other institutions, for a host of reasons, including the opportunity costs of extended education. But even the behavior of poor families with regard to schooling can be linked to social capital. Recent research has pointed to the disadvantageous effects of large concentrations of the poor on constructive social behavior, including school participation (Wilson 1991). Networks of association that are supportive of such activities seem to influence poor people most when their numbers are lower and they are less segregated from other community members (Rosenbaum et al. 1993). Extreme disparities in economic status, and correspondingly large concentrations of poverty, thus can be seen as militating against the development of social capital and contributing to lower levels of involvement with the schools. ${ }^{3}$

As noted earlier, this article also considers a new period, and factors typically associated with enrollment patterns were different. One was the labor force. While it is possible to think of the job market as having been relatively uncomplicated in the past, at least as far as education was concerned, it became more involved with time. The twentieth century witnessed dramatic changes in the urban occupational structure. Industrial employment stabilized, and the number of white-collar workers increased dramatically. Clerks, managers, and professionals of one stripe or another became the largest segment of the nation's workforce in the postwar period (Levy 1987; Long 1958). As Claudia Goldin has noted, these were changes with important implications for the nation's educational system $(1998,1999)$. The appearance of large numbers of relatively well-educated workers, however, complicates the task of analyzing enrollments. While education certainly contributed to the growth of whitecollar employment in the twentieth century, it is unclear how education and employment variables should be considered in assessing variation in enrollment levels. As suggested above, the effect of adult education levels on teen enrollment may have reflected the influence of social capital, regardless of labor market factors.

While much of the research on school attendance has focused on the job market, some studies have considered the impact of ethnicity on school at- 
tendance, focusing on differences in the experiences of various immigrant groups in American history. In general, they have found that certain groups were associated with different levels of teenage school attendance. In the early twentieth century, for example, relatively low rates of secondary enrollment were observed among Italian and Polish immigrants in American cities, while Russian Jewish youth were more likely to attend school than others (Olneck and Lazerson 1974; Perlmann 1988). These patterns can be considered within the framework of ethnocultural explanations of variation in school participation. Simply stated, certain groups seem to have assigned greater value to formal education, other things being equal, than others.

This, of course, also could have been related to the question of social capital. As Goldin and Lawrence Katz have suggested, some communities appear to have been more cohesive than others and seem to have provided greater support for the building and expansion of secondary schools. The values of community members regarding formal education would conceivably have had a substantial impact on such decisions. Ethnic differences in school attendance probably were linked in other ways to degrees of social capital in various groups. Coleman theorized that the influence of particular values is grounded in social networks. If this is true, the cohesiveness of ethnic neighborhoods may have played a role in promoting enrollment, especially for groups that placed a high value on educational attainment."

Finally, there is the question of place. Goldin and Katz also noted that high schools were an expensive investment, so a high degree of consensus was necessary for their establishment, especially in smaller communities. Goldin and Katz tested their ideas with state-level data and evidence from Iowa. However, they did not explore the influence of social capital as it may have been manifest in the nation's largest cities (Goldin and Katz 1999). Utilizing evidence from the federal census, this article will test a number of the propositions they have advanced, looking specifically at urban settings.

\section{Data and Methods}

Examining intercity differences in high school enrollment patterns is an approach well suited to addressing these issues in 1950. Most labor markets, after all, historically have functioned in a particular location. While many people migrated to find work, it is reasonable to assume that students making decisions about leaving school for employment were most immediately influenced by local economic opportunities. For this reason, cities and their corresponding metropolitan areas are appropriate units of analysis for a study of this sort. Social scientists have long noted that cities are characterized by varied occupational profiles, dictated by each locale's function in the larger 


\section{Social Capital and Secondary Schooling}

economy (Guest and Tolnay 1983). Industrial cities, for instance, had large numbers of factory workers, market distribution centers featured service workers, retail centers had store clerks, and governmental cities had disproportionate numbers of clerical workers and professionals. Given the historic dynamics between work and school participation, one would expect to see distinctive patterns of school attendance for teenagers in different types of cities. $^{3}$

It is also true that cities are characterized by particular social and cultural conditions as well. Depending on their location and the nature of the local economy, cities have experienced differing patterns of in-migration and are marked by distinctive ethnic and racial profiles. Thus, cities in the Northeast traditionally have had large numbers of Irish and Italian immigrants, while those in the Midwest seem to have drawn Germans and Poles. Mexicans and Asians were most evident in the Southwest and Pacific coast cities, while the South attracted relatively few immigrants (Tyree 1995). A national sample of major cities, in that case, provides a wide variety of social and cultural settings for the examination of school attendance. If these factors were related to overall patterns of teenage enrollment, it should be evident in the analysis that follows. ${ }^{6}$

As indicated earlier, data for this study were drawn from the U.S. census published volumes for 1950. This census year featured a unique set of tables highlighting the school and work experiences for youth of different age groups for all cities with a metropolitan population greater than $250,000 .^{7}$ Data were collected for each of these places, a process of selection that resulted in a sample of some 75 cities, each in its own metropolitan area. Added to information on school attendance were data on a wide range of other characteristics of these urban areas, including population and labor force variables. Altogether, I have developed four broad classes of variables, each representing a different dimension of urban life linked to factors considered in earlier studies.

Two types of education variables are utilized in the analysis to follow. Teenage school participation was measured by taking the percentage of 16- and 17-year-olds enrolled in school in the central city of each metropolitan area, a figure calculated by the census bureau. Since age grading was ubiquitous at this time, at least in urban areas, this figure generally represents students enrolled in secondary schools in the months immediately preceding the census, which was conducted in April 1950. Individuals enrolled in trade schools and other forms of professional education were not counted by the census in this respect. The chief educational variable, in that case, is an overall rate of school participation for youth ages 16 and 17, which can be considered the inverse of the high school dropout rate. ${ }^{8}$

A second education variable, also calculated by the census, is the median years of schooling attained by the female population age 25 and older. It is a dimension of experience not considered in earlier studies. This factor can 
be interpreted as a measure of general attainment in a city's adult population and as a reflection of past practices and social norms regarding education (male and female adult education levels were correlated at .95). In the latter respect, it might also be considered a representation of community expectations with respect to schooling. As such, it is a broad indicator of human capital in a given locale and is associated with overall levels of wealth. Cities with higher levels of adult attainment generally experienced lower poverty and less inequality, factors associated with social capital by other studies. It is possible that higher adult education levels also contributed to greater social cohesion, insofar as school experiences forged bonds between individuals within a given community. For all of these reasons, it is an important element of the analysis presented below.

Employment variables include the number of men and women employed in each of five major occupational groups: factory operatives (the largest category of industrial employment), clerical workers, service employees (a broad category ranging from domestics to auto repair), retail sales workers, and professionals. Each of these figures includes the total number of men and women employed across each metropolitan area, so that the resulting variable represents a share of the local labor force. Variation within each of these categories can indicate the proportional magnitude of employment opportunities within an urban area, representing the local labor market these teens encountered in a direct and immediate fashion. Yet another category of employment variables concerned the number of teenagers working, representing those participating in the local labor market. Separate variables have been constructed for the labor force participation rates of teenage boys and girls who were not enrolled in school.

Following the lead of studies mentioned above, I also have included a number of ethnocultural variables. The size of each area's black population is one race/ethnicity variable, for instance, representing a factor that certainly has been an important element in the history of American education. Traditionally, African Americans were required to attend segregated schools in many parts of the country, and the schools that were available to them typically were afforded fewer resources. The nation's black population was still heavily concentrated in the South in 1950 and may have had limited access to secondary education. But substantial numbers of African Americans lived in cities elsewhere, too.

Other ethnocultural variables concern various immigrant groups. This period was nearly four decades removed from the last years of large-scale immigration in the early twentieth century, but data on major ethnic groups were provided by the census for each urbanized area. In 1950 these data were described as the country of origin for the foreign-born population, provided for all metropolitan areas outside of the South (1960 data were utilized for 


\section{Social Capital and Secondary Schooling}

southern cities). For each group the relevant variable is a measure of the size of each group's share of the local ethnic population. Data were collected for six groups: Irish, Italians, Poles, Russians, Asians (largely Chinese and Japanese), and Mexicans. ${ }^{9}$ Another variable measured the size of the local ethnic population (those of foreign parentage).

Additionally, a number of "structural" variables were included to represent yet other facets of urban life. Regional dummy variables were constructed to measure the independent effect of geographic differences in culture and tastes regarding education. As suggested above, there is a long history of regional variation in schooling practices, independent of other social and economic forces. This type of variable has been created for cities in the Southeast, the Northeast (New England and New York), and the Far West (Pacific states). Altogether, cities in these regions constituted fewer than half of the cities in the sample, but they represent a number of culturally distinctive urban milieus, especially with regard to education.

City size is yet another structural factor, a variable intended to measure the independent effects of large and small urban areas. Recent research has suggested that secondary enrollments were higher in smaller communities (Goldin and Katz 1999). This too may be a reflection of social capital, at least in part. A long tradition in urban scholarship suggests that larger places exhibit less overall social cohesion (Hawley and Zimmer 1970). This is thought to be at least partly a function of the strength of relationships and corresponding social networks, key elements of social capital. City size, in that case, can be considered a structural feature of urban life, independent of other social and economic characteristics of cities (Cook and Beck 1991).

Finally, there is the question of financial resources and equity. In particular, poverty is yet another facet of urban life that has been linked in research to patterns of secondary school enrollment (Rumberger 1983). In this study, poverty levels are measured by calculating the portion of a city's households with an income below $\$ 1,000$, less than half the median household income nationally at the time. As indicated earlier, this variable is related to the degree of the degree of economic inequity in a particular urban area, another factor linked to social capital in other studies. Concentrations of poverty are hypothesized to represent barriers to the development of social networks of the type that Coleman and others considered important to the formation of social capital. In their research, for instance, Goldin and Katz found places with fewer residents at a given threshold of wealth (automobile ownership) exhibited less civic cohesion and a correspondingly diminished commitment to education (Goldin and Katz 1999).

These variables are examined in a series of analyses, including discussion of descriptive data (regional means), a bivariate correlation matrix, and a model utilizing ordinary least squares (OLS) regression. In the latter analysis, 
separate models are calculated for various groups of variables. To begin, however, it is important to discuss general characteristics of the sample cities in the three principal regional groupings mentioned earlier.

\section{Historical Context: Regional Patterns of Development}

Historically, urban development in the United States has been shaped by the influence of culturally and economically distinctive regions. This is well known among urban historians. The industrial North became the country's dominant section following the Givil War, an event that also marked the South's relative economic and social isolation. In the twentieth century, the Great Lakes (or North Central) region industrialized rapidly and developed in a pattern similar to the Northeast. The Western states also grew quickly during this time, although not through classic industrialization. Rather, they represented a more balanced pattern of growth, drawing on a variety of economic activities ranging from commercial agriculture to shipping and processing raw materials to light manufacturing. In many respects, the residents of the West successfully combined the agricultural focus of the South with the industrial strengths of the North, while avoiding many of the problems associated with each path to development (Perloff et al. 1960).

As noted earlier, prior studies have shown that each of these distinctive areas was associated with a different pattern of teenage school attendance early in the twentieth century. Teenage enrollments were lowest in the Northeast, where industrial employment drew young men and women away from school. Enrollments were historically high in the West, where relatively few industrial jobs existed and professional and clerical positions appeared in greater numbers. In the largely agricultural South, teenage enrollments were moderately high, although it is not clear that the quality of schooling there was comparable to other regions (Rury 1984, 1991). In the most recent analysis of these trends, Goldin and Katz have noted the existence of similar patterns as late as 1940. In particular, they pointed to the relatively high levels of secondary enrollment in the Great Plains states and the Far West, labeling these regions the "education belt" (Goldin and Katz 1999).

Goldin and Katz did not focus on enrollment in larger cities, but it appears that urban teenagers exhibited the same general tendencies in the mid-twentieth century. Evidence of these patterns can be seen in table 1, which presents data on regional characteristics of cities in the sample selected for this study. The factors selected for display in this table and the next are a sampling of the variables that will be considered later in the article and are intended to help illustrate general tendencies in the data. These figures show many of the characteristics of cities in different parts of the country at midcentury. The 
Social Capital and Secondary Schooling

TABLE 1

Regional Means, Sample Cities, 1950

\begin{tabular}{lcccc}
\hline & National & Northeast & South & West \\
\hline Female enrollment, age 16 & .77 & .79 & .73 & .83 \\
Adult education (years) & 10.4 & 9.7 & 10.0 & 11.7 \\
Poverty rate & .06 & .06 & .07 & .05 \\
Female teen labor force & & & & \\
$\quad$ participation & .38 & .51 & .34 & .27 \\
Female clerical employment & .31 & .29 & .31 & .33 \\
Female operatives & .18 & .29 & .13 & .11 \\
Female service employment & .125 & .09 & .14 & .13 \\
Female sales employment & .087 & .077 & .08 & .093 \\
Black population & .089 & .03 & .23 & .04 \\
\hline
\end{tabular}

number of male and female factory operatives, for instance, was highest in the cities of the Northeast and lower in the South and West. At the same time, the proportion of each city's population that was African American was much higher in the South than in the other regions. While there does not seem to have been much variation in other employment variables (white-collar and service employment was a slightly smaller share in the Northeast, a corollary of high industrial employment), there was considerable variation in the labor force participation rates of 16-year-olds not enrolled in school. Interestingly, the labor-force participation rates for these teens were considerably higher for males than females, but the regional patterns of variation differed markedly. Employment rates were highest for males in cities in the West, while the highest corresponding rate for females was highest in the urban Northeast. This suggests that industrial employment may have been especially important for young women leaving high school, while a somewhat broader range of work options were available to the boys.

By and large, patterns of city school attendance seem to have followed the general tendencies identified earlier. Enrollment levels were highest for urban teens in the West, but they were lowest in the Northeast, perhaps representing the historic association of low teen attendance with industrial employment. Enrollments in southeastern cities also were lower than the average for the sample as a whole, confirming the legacy of low attendance patterns in that region also. As far as urban high school enrollments were concerned, regional distinctions still appear to have been quite pronounced at midcentury, even in the country's big cities.

These general patterns are also evident in table 2, which presents a correlation matrix of principal variables from the foregoing discussion. Only a handful of these relationships are robust, but their relative magnitude and 
TABLE 2

Correlations

\begin{tabular}{|c|c|c|c|c|c|}
\hline & High School & North & West & South & Clerical \\
\hline $\begin{array}{l}\text { North } \\
\text { West } \\
\text { South } \\
\text { Clerical } \\
\text { Factory } \\
\text { Ethnic } \\
\text { Irish } \\
\text { Mexican } \\
\text { Black } \\
\text { Adult schooling }\end{array}$ & $\begin{array}{r}-.006 \\
.499 \\
-.254 \\
-.168 \\
-.095 \\
.053 \\
-.165 \\
-.286 \\
-.532 \\
.346\end{array}$ & $\begin{array}{r}-.198 \\
.431 \\
.429 \\
.487 \\
-.143 \\
-.374 \\
-.348\end{array}$ & $\begin{array}{r}-.036 \\
-.350 \\
.058 \\
-.159 \\
.064 \\
-.200 \\
.476\end{array}$ & $\begin{array}{r}.071 \\
-.193 \\
.080 \\
.118 \\
-.085 \\
.454 \\
-.101\end{array}$ & $\begin{array}{r}-.391 \\
-.259 \\
.123 \\
.005 \\
.268 \\
.480\end{array}$ \\
\hline & Factory & Ethnic & Irish & Mexican & Black \\
\hline $\begin{array}{l}\text { North } \\
\text { West } \\
\text { South } \\
\text { Clerical } \\
\text { Factory }\end{array}$ & & & & & \\
\hline $\begin{array}{l}\text { Ethnic } \\
\text { Irish } \\
\text { Mexican } \\
\text { Black } \\
\text { Adult schooling }\end{array}$ & $\begin{array}{r}.094 \\
-.027 \\
-.128 \\
-.269 \\
-.473\end{array}$ & $\begin{array}{r}.646 \\
.190 \\
-.227 \\
-.085\end{array}$ & $\begin{array}{r}-.059 \\
-.019 \\
.016\end{array}$ & $\begin{array}{l}-.021 \\
-.032\end{array}$ & -.139 \\
\hline
\end{tabular}

direction is telling in a number of respects. First, the regional tendencies evident in table 1 are borne out in several relationships. Factory employment was positively associated with the Northeast dummy variable and negatively with variables for cities in the Southeast and West. Employment for 16-year-old males, however, was negatively associated both with the Northeast and factory employment, but positively related to the West. The size of the black population was positively linked to the Southeast and negatively with other regions, and the ethnic population was associated positively with the Northeast and appears to have been unrelated to the other regional groups of cities. Not surprisingly, the relationship between the size of the Irish and larger ethnic populations was strong and positive, while both of these variables were negatively associated with the black population. These coefficients also doubtlessly reflect underlying regional differences that distinguished the cities in the sample, as do many other factors in the matrix.

The education variables in table 2 also are telling. Both high school enrollments and adult education levels (expressed in average years of schooling for women) exhibit distinctive regional variation. As expected, both variables 


\section{Social Capital and Secondary Schooling}

were positively associated with the West and negatively with the Southeast. Adult education levels were negatively related with the Northeast, however, perhaps because of the region's historically large ethnic population and high levels of industrial employment. Most of the ethnic and employment variables in the matrix were negatively related to high school enrollment levels. Yet it is hardly a surprise that the two education variables were themselves positively associated. Given the assumptions described above, one would expect to find higher rates of high school enrollment in cities with relatively well-educated adults. As suggested earlier, this may well indicate a degree of community commitment to education, a reflection of social capital operating to support schooling.

A number of additional relationships not reported in table 2 are worth noting. Not surprisingly, the correlation between adult education levels and poverty was negative, and the association was significant but moderate in strength (-.4). Gities with higher levels of education, after all, would be expected to have lower levels of poverty, and places with large numbers of poor families should have had lower overall attainment, all other things being equal. Interestingly, there was no statistically significant pattern of association between poverty levels in these cities and rates of employment for teens not in school; coefficients for both males and females were -.13. This suggests that the opportunity costs of secondary schooling were not a major disincentive to attendance in cities with large numbers of poor residents, as these places did not have unusually high numbers of unenrolled youth in the labor force. It is possible, in that case, that the impact of poverty on schooling reflected the effect of social capital deficits as much or more than simply economic deprivation. The correlation between poverty and secondary enrollment was significant and negative, and approximately of the same order of magnitude as the association between enrollment and adult education in table 2 (.3). Controlling for youth employment did not change this pattern of association, except to strengthen it slightly. The negative relation of poverty to secondary schooling at this time appears to have been largely independent of labor market factors and thus points to social capital as an explanatory factor.

Altogether, the information in tables 1 and 2 point to the prevailing forces of regional differentiation that continued to influence the development of American cities at the midpoint of the twentieth century. Teenage school enrollment patterns were shaped by these forces but also were linked to intercity variation in ethnic composition and labor force characteristics. To establish the relative importance of these various elements, it is necessary to utilize a more sophisticated form of analysis. This step, undertaken next, will confirm some of these tendencies and introduce yet additional factors that influenced secondary education. 
Enrollment, Work, Ethnicity, and Social Capital: A Regression Analysis

To further examine the link between school participation and employment profiles in the nation's major cities in 1950, I have constructed a series of regression equations with the variables introduced above. These are presented in table 3 , which lists standardized regression (or beta) coefficients and provides information on statistical significance and tolerance levels for each predictor. The dependent variable in each instance is the proportion of central city 16and 17-year-olds enrolled in school, a figure that can be considered the inverse of the dropout rate. As noted earlier, variables representing each of the groups of factors discussed earlier have been included, with the table's final column presenting a full model representing all of them. This exercise is intended to test the various relationships discussed above and to assess different explanations of interurban variation in high school enrollment in 1950.

Statistical analyses of aggregate data such as these often encounter problems of multicollinearity. As suggested by the tolerance coefficients in table 3, collinearity is certainly evident in the regressions presented therein but at levels that are acceptable under the assumptions of this analytical technique. One important test of collinearity (not reported in table 3) is captured by another measure, known as the Variance Inflation Factor, or VIF. The highest VIF value in model 3 is 3.1 , well below the critical threshold of 3.5 dictated by the overall $R^{2}$ value of the equation in model 3. This indicates that each of the independent variables is more strongly associated with the dependent variable than with other independent factors in the model. In addition to this, the Durban-Watson measure of collinearity among the residuals in each of these models also fell within the acceptable range. Finally, the variables were not correlated with the residuals for these models. While some degree of collinearity is inevitable in analyses of this sort, it does not seem to have posed a problem for the regressions reported in table $3 .^{10}$

As mentioned above, the results of analysis are presented in three stages, successively building upon one another. The first of these features historical and structural elements of urban development. These include population size (logarithmically adjusted for skewness), education levels of the adult population (women only), and poverty levels (proportion of households with income below $\$ 1,000$ ), along with several regional dummy variables. The first three variables can be associated with the social capital argument offered by Goldin and Katz. As noted earlier, larger cities with lower numbers of educated adults and higher rates of poverty can be hypothesized to exhibit less social cohesion around civic issues such as schooling. Goldin and Katz also suggested that ethnic homogeneity was associated with greater social capital, but this will be con- 
TABLE 3

\section{Regression Models}

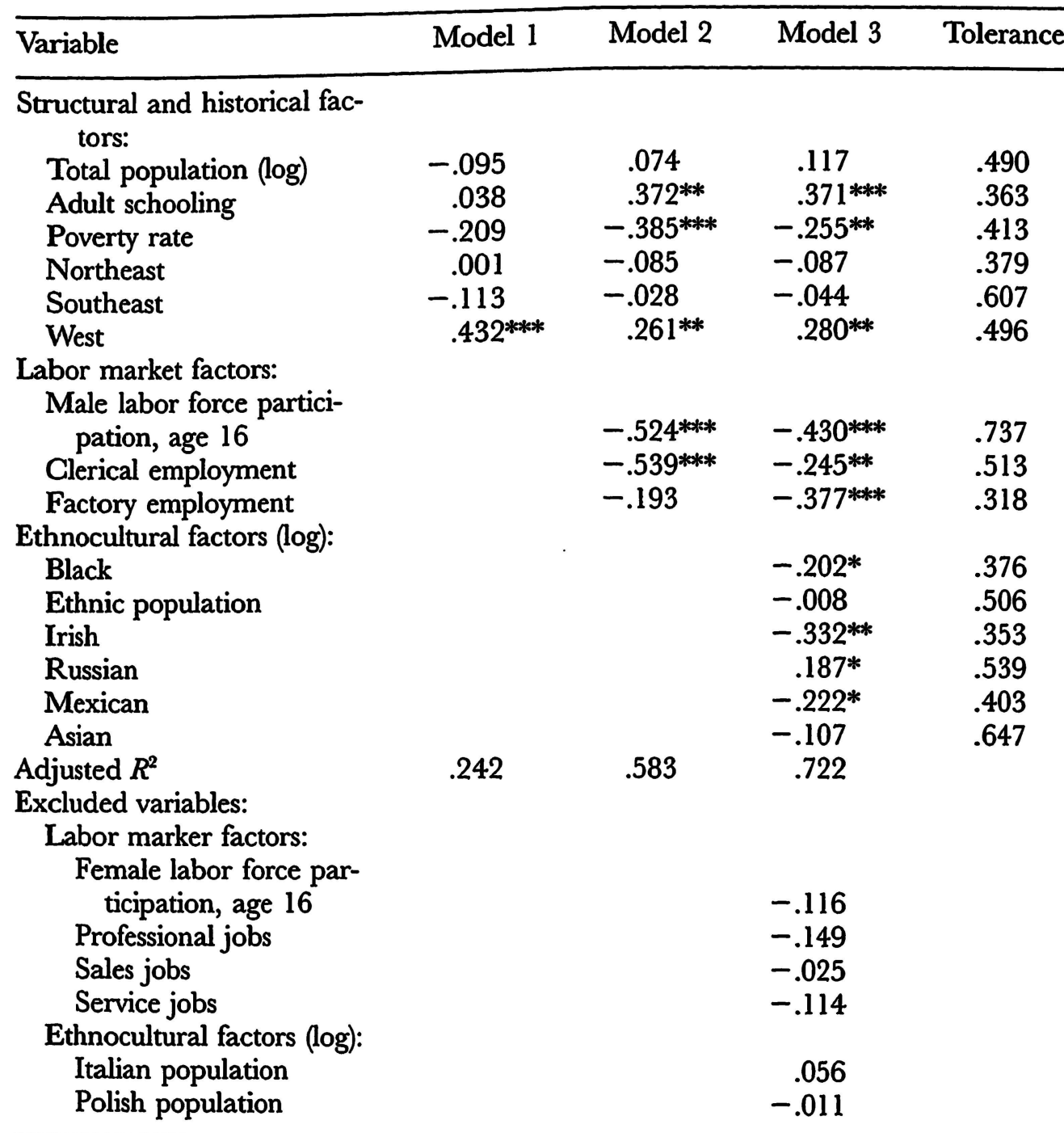

NoTE.-Figures are standardized OLS regression coefficients (beta). All significance tests are two tailed.

* Significant at the .05 level.

** Significant at the 0.005 level.

*** Significant at the 0.001 level. 
sidered in connection with the third block of variables included in the model below.

The other blocks of variables in table 3 are associated with the labor markets and ethnic profiles of American cities in 1950. Three labor market variables are included in model 2, the labor force participation rate of 16-year-old males not in school, and overall levels of employment in clerical and factory (operatives) employment. Ethnocultural factors include the size of the black and ethnic (of foreign parentage) population, along with the share of the ethnic population represented by a number of different groups. The groups in model 3 include the Irish, Russians, Mexicans, and Asians. Logarithmic functions also were used to correct for skewness in the distributions of these variables, an artifact of the wide regional differences evident in tables 1 and 2. Additional labor market and ethnicity variables that were considered in the analysis, but excluded because of their weak performance, are listed among the "excluded variables" at the bottom of table 3 .

The results of this analysis demonstrated the importance of these clusters of factors. In each of the models a number of variables exhibited strong relationships with high school enrollment. In model 1 , for instance, the strong, positive regional effect of the West was evident, along with the negative effect of poverty levels on enrollment rates. Model 2 demonstrated the importance of certain labor market factors, along with adult education levels, and model 3 pointed to the influence of ethnocultural influences on enrollment rates. As suggested by the adjusted $R^{2}$ figures at the bottom of the table, each block of variables was associated with a sizable portion of the total interurban variation in enrollment rates."

By and large, the signs on these factors were consistent with the results of earlier studies. This certainly was the case with the variables in the first grouping. While city size was not important in any of the models, both adult education levels and poverty rates were significant in models 2 and 3. As expected, the sign on education levels was positive, while it was negative for poverty rates. These results support the social capital argument offered by Goldin and Katz. While they found a negative relationship between inequality levels and enrollment, this analysis employs two related constructs that point to similar patterns. As noted earlier, poverty is a critical aspect of inequality, and a positive relationship with adult attainment levels suggests that expectations regarding education were successfully communicated from one generation to the next, a critical dimension of social capital. In these respects, such findings confirm important elements of the Goldin and Katz thesis. Other things being equal, cities with high levels of adult education and relatively low rates of poverty exhibited higher secondary enrollments. This was true even when controlling for the effect of cities on the West Coast, many of which exhibited these characteristics themselves. This is can be seen as evi- 


\section{Social Capital and Secondary Schooling}

dence of the impact of social capital on enrollments. Even so, the West dummy variable retained its significance in all three models, suggesting that enrollments were even higher in those cities than these factors alone would predict.

Other coefficients reported in table 3 also are consistent with expectations, with some qualifications. As a rule, employment variables were negatively associated with high school enrollment, as were most of the ethnic variables. This suggests that various types of jobs continued to exert some appeal to teenagers, despite the advent of child labor laws and the industrial trade union movement of the 1930s. Not surprisingly, teen employment also was negatively associated with school attendance, especially for males. Simply put, the larger the number of male adolescents working outside of school, the greater the number of dropouts. In addition to this, it seems that the local availability of factory jobs was associated with larger numbers of teens leaving school, even if industrial employment may have become a bit more difficult to secure for teenagers.

Other forms of relatively low-skill employment also appear to have been important, particularly clerical work, a job category historically associated with higher enrollments. There is evidence, however, that many clerical jobs had become routinized by 1950, requiring fewer skills and formal credentials. Historians have described the development of a hierarchy of these positions, as entry-level jobs such as filing and routine typing became more commonplace. These positions often did not require a diploma and were available with little experience apart from typing ability, certified by a standard test. Goldin (1999) has noted that the wage premium associated with clerical employment dropped significantly in the first half of the century, especially for men. This no doubt reduced the incentive to remain in school for such jobs. Moreover, it was easy to obtain training at special clerical schools or business institutes, or with a few clerical courses available in high schools. The existence of routine clerical jobs may have made school even less appealing to youth eager to leave before graduation, especially in cities where the demand for these workers was quite high. ${ }^{12}$

There also was considerable variation with respect to race and ethnicity. As expected, there was a negative association between the size of a city's black population and overall enrollment levels, even controlling for regional effects and employment factors. In 1950 this may have been at least partly due to the limited number of black high schools, particularly in southern cities. Historians have noted the relatively low number of high schools available to African Americans in the South at this time. Black migrants to the cities, including many teenagers, often went in search of work, a fact that did not help secondary school enrollments (Anderson 1988). ${ }^{13}$ Given this, it is little wonder that a negative relationship of this sort was evident, even though it was not an overly strong association. It represented the start of a new chapter 
in the history of urban education, one that came to increasingly feature race as a central element of school experiences.

Other ethnic patterns of association are more striking. As noted above, there was a strong negative association of teen enrollments and Irish population in 1950, an unexpected development in light of studies pointing to relatively high levels of Irish school participation in earlier periods. There was an equally salient negative association with the Mexican population, a finding more in line with other studies. Conversely, there was a mildly positive association between the size of the Russian population and high school enrollment, also a result in keeping with earlier patterns (Olneck and Lazerson 1974; Perlmann 1988). The effect of other ethnic groups on overall enrollment rates appears to have been negligible, although there was a weakly negative association with the size of the Asian population.

By and large, in that case, the results of this analysis confirm the findings of earlier studies, but with a few caveats. There is clear evidence of the influence of social capital, but employment and ethnic variables also appear to have affected secondary enrollment levels in major American cities in 1950. While certain relationships are difficult to explain, such as the negative sign on the Irish population variable, the others appear to follow well-established tendencies in the history of urban education. Taking a closer look at the data, however, seems to suggest a somewhat more complicated picture.

\section{Secondary Education as a Norm: Social Capital in Urban Settings}

As suggested earlier, the labor markets and urban milieus that teenagers encountered in 1950 were considerably more complex than those previous generations of urban adolescents had known. Industrial employment had changed with unionization and the evolution of new customs about hiring youth. Clerical work, once associated with higher enrollment, appeared to draw teens away from the schools, perhaps to take jobs that did not require a diploma. At the same time, ethnicity also entered into the picture. It was hardly a surprise to find lower enrollment levels in places with large black and Mexican populations, given historic patterns of discrimination against these groups, but the strong negative association with the Irish is puzzling. In the case of other European ethnic groups, Russians, Poles, and Italians, familiar patterns of schooling were evident, or there was no evident relationship. And then there is the question of social capital and related elements of urban life. While city size was not important in the foregoing analysis, adult education levels and poverty rates both were clearly related to high school enrollment. All of this suggests that places mattered in multiple ways, and that differing arrays of factors may have influenced school participation in various locations. 


\section{Social Capital and Secondary Schooling}

The regression analysis presented in table 3 offers an abstract account of how these various factors were related to high school enrollment levels. But there remains the question of how this set of relationships looked in historical reality, in the urban environments that teenagers faced as they made decisions to stay in school or drop out. To address this, it is necessary to link the foregoing discussion to a consideration of particular places. With respect to social capital, it is possible in this way to point to different manifestations of this factor in various settings. As will become evident below, however, this is a knotty question.

To begin, it is necessary to consider the various dimensions of urban experience related to school enrollment decisions and link them to specific cities. As it turns out, there were several different types of urban milieus that can be identified using the factors presented in table 3 . Consider the question of local labor markets. Certain cities were marked by a traditional pattern of high manufacturing employment and low school enrollment, such as Providence, Rhode Island, or Baltimore, but there were others where industrial employment does not appear to have inhibited attendance, such as Milwaukee, Wisconsin; Johnstown, Pennsylvania; and Youngstown, Ohio. Interestingly, these manufacturing towns with elevated enrollments also had relatively low levels of clerical employment and small Irish communities. These factors may help to explain relatively high levels of enrollment, but it is possible that other, less tangible influences were at work too.

In many respects, industrial cities with high secondary enrollment present a historical riddle. In addition to the places just mentioned, they included towns such as Allentown, Pennsylvania; Flint, Michigan; and Duluth, Minnesota. These were not especially large cities, with the obvious exception of Milwaukee, and they were heavily unionized in 1950. Even though they did not have high levels of adult education, each one registered enrollment rates for 16- and 17-year-olds in excess of 80 percent, well above the population mean. This suggests a good deal of socially sanctioned support for education, which may have represented a form of social capital. In many such places, there is evidence that local high schools had become important community institutions, and this undoubtedly helped to boost enrollments. Somehow, it seems that attending high school had become something of a cultural norm, and comparatively few teens dropped out. In the context of a relatively cohesive community, perhaps bound by the values and expectations of the industrial union movement, with strong social networks emanating from shared experiences, social capital seems to have become a potent force in promoting high school enrollment in such places. ${ }^{14}$

If the high enrollment manufacturing town was one urban milieu that seems to have encouraged high school attendance in 1950, yet another one featured a mixture of high adult education and low poverty, with relatively low levels 
of social diversity. This was similar to the community profile offered in the Goldin and Katz social capital explanation, except here it was set in larger urban settings. This category included places such as Salt Lake City, Miami, and Minneapolis, as well as such West Coast cities as Seattle, Portland, and Los Angeles. These clearly were not small, cohesive communities, but they had unusually high education levels among adults and relatively little ethnic diversity. They did not have large numbers of industrial workers, and most did not have unusually high levels of clerical employment either. In addition to this, as a group they exhibited low rates of poverty compared with other cities in the sample, an indicator of greater overall economic equality. All of these features together seem to have contributed to a pattern of social cohesion that encouraged high school attendance. This can be interpreted as evidence of yet another manifestation of social capital and a communal atmosphere that supported positive relationships between adults and children, helped neighborhood associations and networks to develop, and encouraged attainment levels. Each of these cities placed well above the national average in terms of teenage enrollment rates, despite their size and level of development as urban centers. Here too, going to high school seemingly had become a community norm, and dropout rates were relatively low.

If social capital was one of the characteristics of cities with high levels of secondary attendance, what about other places? What of the cities where high schools seem to have struggled in 1950? As noted above, there clearly was a good deal of regional variation in enrollments, so it is not surprising that Atlanta, Dallas, and Baltimore featured some of the lowest attendance rates among 16- and 17-year-olds in the entire sample, each less than 68 percent. They were joined by San Antonio and St. Louis, cities with peculiar ethnic and employment profiles. Like many other southern and border cities, they had considerable racial and ethnic diversity and above-average levels of poverty, factors that militated against the development of social networks that could support education. Places with relatively large numbers of clerical workers, such as Washington, D.C., and Kansas City, also were marked by lower than average enrollment rates. Poverty levels were higher in cities like Birmingham, Memphis, and Tampa, and teen employment was prevalent in Jacksonville, Norfolk, and Fort Worth, all located in the South. Altogether, it appears that a number of factors accounted for low enrollments in cities such as these.

These patterns undoubtedly contributed to the region's relatively weak performance with regard to secondary education. In these cities there may have been less community consensus about the importance of the secondary education, but the schools also lost large numbers of teens to the labor market. In such cities as many as a third of 16- and 17-year-olds did not attend school in 1950. High school enrollment in these settings probably was not a widely 


\section{Social Capital and Secondary Schooling}

recognized community norm, but the role of social capital is hardly clear. Relatively high poverty levels and low adult educational attainment may have resulted in less community cohesion, but other factors also drew teens away from school. Altogether, it probably is safe to hypothesize that social capital was less important in these contexts, at least with regard to secondary enrollment, and that, whether by necessity or choice, many urban youth were concerned with pursuits other than school.

Finally, there is the question of the ethnicity and the curious behavior of the Irish in the analysis discussed earlier. While other patterns of ethnic behavior were consistent with expectations, the striking negative association of the size of Irish communities and enrollment levels reported in table 3 is difficult to explain. By and large, places with relatively large Irish populations did not exhibit unusually low high school attendance rates. Such leading Irish centers as Boston, Springfield, Worcester, New Haven, and New York all featured enrollment levels in the 76-79 percent range, average or slightly above. There was a discernible pattern, however, at the other end of the distribution: cities with relatively small Irish communities had the highest attendance rates. This was true of the high-enrollment manufacturing cities of the Midwest and of the high-attendance, low-poverty cities of the Far West. In addition to this, the Irish tended to be located in larger places, cities with higher levels of clerical employment and bigger ethnic populations.

Still, the negative association between the Irish and high school attendance was independent of other factors, and thus is difficult to explain. The size of the Russian population also was correlated with many of the same factors, and yet the sign on this variable was positive. As suggested above, this is not a surprise, as Russian (mainly Jewish) children had exhibited high levels of attendance throughout the century. Historians have pointed to social cohesion and community values in support of education as factors promoting achievement among Russian Jews, a classic example of the influence of social capital. The Irish also lived in cohesive communities, of course, and had not been known to leave the schools early, but this may have changed by 1950. It is a fair question, in that case, to ask just how social capital may have figured in the Irish experience.

One explanation is that Irish communities exhibited forms of what Alejandro Portes has described as "negative" social capital, relationships and values that militated against formal education (1998). This could be true if the Irish possessed high stocks of social capital, but not the sort that promoted high school enrollment. This would be manifest in the case of high social cohesion and shared values, but low degrees of school engagement. Historians have observed, for instance, that the Irish were more heavily concentrated in certain occupations than other immigrant groups, most of which did not call for high levels of formal education. In Boston, according to Kevin Kenny, 
they held "three times their share of unskilled laboring jobs, and disproportionately fewer professional, managerial, and proprietorship positions" (2000, p. 226). Similar patterns were evident elsewhere, especially in cities where their numbers were relatively high, such as Worcester or even New York and Philadelphia. Suzanne Model has suggested that the New York Irish benefited from associations with certain occupational niches that made them less dependent on educational attainment for social advancement. Some Irish teens may have relied upon contacts and political ties, well-established social networks in many cities, to secure employment rather than formal schooling (Model 1993). Kenny also notes that both Irish men and women were overrepresented in "protective services" (police and fire services), long-standing preserves of machine patronage in big cities. ${ }^{15}$ It also is possible that there were gender dimensions to this story: Irish teenage girls were more likely than their counterparts from other ethnic backgrounds to leave school for work, an explanation supported by correlations not reported in table 2 . Such patterns of behavior suggest that a certain type of social capital was important in many Irish communities, relationships, and networks of association focused on gaining access to trades and political patronage rather than encouraging formal schooling. If so, the Irish experience may have been a case of social capital not working to promote enrollment but instead helping teens succeed in a particular type of urban milieu without need for formal educational credentials. This too can be taken as evidence of social capital, but not the sort associated with schooling.

Given this, it is possible that it was the Irishness of a place that was important. In cities with large Irish populations, perhaps formal credentials were less important than elsewhere, especially if the occupational recruitment regimes identified by Kenny and other historians predominated there. In these contexts social capital was more important for access to certain job opportunities and the groups that controlled them than it was for attending high school. Such an explanation is consistent with the striking patterns identified in table 3. All things being equal, places with large Irish populations exhibited lower levels of high school enrollment. This too was a part of the urban milieu that confronted teens in 1950, one that contemporaries and historians alike had failed to note. ${ }^{16}$

\section{Conclusion}

By and large, the analyses above confirm a continuing relationship between schooling, ethnicity, and employment for high school-age adolescents in the immediate postwar United States, at least in the nation's major cities. In particular, the long-standing negative relationship between industrial devel- 


\section{Social Capital and Secondary Schooling}

opment and school attendance was still in evidence in 1950, but other forms of employment had come to serve as an inducement for young men and women to leave school, particularly office work. Regional influences were also important for high school enrollments, as cities in the West continued to lead the rest of the country. The effect of ethnicity was important also, even if there were wide regional differences in the distribution of various ethnic groups. And a variety of additional factors also appear to have influenced secondary enrollments.

Taken together, the results of this analysis suggest that place did indeed matter as regarded school enrollments in the postwar period. As indicated in the adjusted $R^{2}$ coefficients, a substantial portion of the variance is explained by most of these models. What is striking, however, is the extent to which high school enrollment appears to have become a norm in certain cities, in spite of local labor market and ethnic factors that influenced educational behavior in earlier times and perhaps in other places. Here the influence of social capital, representing varying levels of social cohesion in these communities, was evident. Living in places with high levels of industrial and clerical employment suppressed school participation, even controlling for regional differences, but in some industrial cities enrollment levels were quite high. It was in these latter places, most of them rather small, that the positive effects of social networks of association may have been most evident. The crosssectional nature of this analysis prohibits determination of causal relationships in these patterns of association, but it is clear that the negative influence of the industrial urban milieu had been mitigated in some instances. While the local labor market probably continued to create a context for decisions about school participation, community expectations regarding formal education appear to have entered into the picture as well. As in earlier times, different kinds of places were characterized by high and low rates of teenage school participation in the immediate postwar period, but rising expectations about the high school as a social institution clearly affected some communities too.

Here it is possible to see the influence of social capital as a factor in determining city level enrollment rates. With regard to educational attainment, it paid to live in a community with relatively high adult levels of education and low poverty rates. In such places there was little ambiguity about expectations regarding school attendance, and the signs on these variables were consistent with the effects of social capital in other studies. It was these places that exhibited the highest levels of school enrollment, along with the correspondingly good job prospects. It generally did not pay to be living in the South, however, or in communities with large numbers of teens in the labor force. There the pressures to leave school early appear to have been especially great, and the long-term economic prospects may not have been very promising either. While robust social networks no doubt existed, they probably did 
not extend across the community and were correspondingly constrained in effecting education. And it certainly did not pay to be black or Mexican at this time, at least with respect to attending high school. Social capital may have existed in these communities too, of course, but it does not appear to have helped overall levels of enrollment. Issues of discrimination and inadequate access no doubt contributed to lower enrollment rates for these youth. Ethnicity may have been an educationally important factor for other groups, such as the Irish, but for these non-white youth it undoubtedly was especially significant, regardless of their communities' views regarding schooling. In each of these respects, the characteristics of place, including the sort of social cohesion that yielded relevant stocks of social capital, did much to determine overall levels of teenage school participation, representing yet another dimension of a continuing American tradition of social, educational, and economic inequality.

Notes

DePaul University faculty research grants supported this project. Aaron Rury, Derek Rury, and Neil Sullivan collected data. Bruce Baker, Craig Campbell, Susan Dauber, Tyler Khademan, Sylvia Mendez, Regina Werum, and three anonymous reviewers commented on various drafts. Earlier versions were presented at meetings of the International Standing Conference on the History of Education, Paris, July 2002, and the American Educational Research Association, Chicago, April 2003.

1. The literature on social capital has become quite large and diverse, and the concept has been the subject of considerable debate, particularly with regard to its manifestations at different levels of social aggregation. For an overview of these issues and a commentary, see Portes (2000).

2. The literature is rather extensive. See Walters (1986); Walters and James (1992); Walters and O'Connell (1988). For similar studies of earlier periods, see Fuller (1983); Kaestle and Vinovskis (1980); Rury (1984).

3. William Julius Wilson (1987, chap. 2) has referred to the deleterious effects of large numbers of city residents in dire poverty as "concentration effects."

4. This view is perhaps most clearly represented in Perlmann (1988). Also see Olneck and Lazerson (1974, pp. 155-83) and Rury (1984).

5. To address the question of movement between cities in the present study, an analysis of the size of age cohorts was performed across the 75 cities in the sample. Differences in the sizes of cohorts for males ages 16,18 , and 19 across the sample were less than 10 percent on average, with the largest cases being military centers such as San Diego and Norfolk, containing substantial numbers of military inductees. Across the sample, cohort sizes were correlated at .95 or higher. This indicates that interurban differences in enrollment rates for 16- and 17-year-olds probably were not a function of teenagers moving into particular cities looking for employment. Finally, the analysis below controls for unenrolled male teen employment levels, which should capture much of the effect of any interurban migration of teens seeking work. For similar studies at this level of aggregation or higher, see Fuller (1983). Additional perspective is offered by Richardson (1980, 1984). 


\section{Social Capital and Secondary Schooling}

6. On regional differences in secondary school enrollments in the early twentieth century, see Rury (1985).

7. These data on each city can be found in table 71 of the individual state volumes of the U.S. census (U.S. Bureau of the Census 1951).

8. Census definitions of enrollment at this time embraced "any type of day or night school, public or parochial, or other private school in the regular school system." Moreover, it was specified that "persons enrolled in special schools not in the regular school system, such as trade schools, business colleges, or extension schools, and not included in enrollment figures. Persons enrolled in classes which do not require physical presence in school, such as correspondence courses or other courses of independent study, and training courses given directly on the job, are not reported as enrolled in school." See U.S. Bureau of the Census $(1947$, p. 3). Given this, it is reasonable to assume that the vast majority of students ages 16 and 17 counted in this article were enrolled in secondary schools.

9. For an overview of ethnic change in U.S. cities during the twentieth century, see Tyree (1995).

10. On addressing problems of multicollinearity in regression analysis, see Freund and Wilson (1998, pp. 192-94); and Von Eye and Schuster (1998, pp. 138-41).

11. To test the robustness of these findings, the model was run on a subsample of fifty cities selected randomly from the original group of 77 . While some significance levels were lower, the relative magnitude of all major variables was unaffected by this exercise, and $R^{2}$ levels were comparable.

12. See, e.g., Goldin (1998). On the question of educational requirements for clerical work, see Golden (1999). She is careful to note in reference to an earlier period "that clerical employment was often open to many who had several years of high school but no diploma" (p. S81). She also reports that a large sample of male clerical workers from the 1940 U.S. census "had a median education of 12 years and a mean of 11.72" (p. S83), indicating that a large fraction had not finished high school. On stratification within clerical employment, see Fine (1990, chap. 8); and Cohen (1992, chaps. 5-6).

13. James $D$. Anderson has noted that just 23 percent of eligible black teenagers were enrolled in high school in southern states in 1940, as opposed to more than half of eligible whites, a situation he attributes to the restricted availability of schools (1988, pp. 235-37). On migration patterns and work, see, e.g., Duncan and Duncan (1957, chap. 1).

14. While there is no systematic study of this phenomenon, there is piecemeal evidence of the increased importance assigned to education in these communities. In a study focused on Johnstown, Pennsylvania's small Jewish population, Ewa Morawska (1996, pp. 86-88) identified a dramatic increase in high school attendance during the depression decade among the city's youth. She reports enrollment rates of eighty percent for all 16- and 17-year-olds in the thirties, up from 33 percent a decade earlier, and ninety percent for Jews, up from sixty percent. John Bodnar also has recorded a change in attitudes regarding education. He quotes coal miner Tom Luketich noting that the immigrant workers "started to educate their kids" and the second generation started taking positions as foremen, engineers, and teachers. Luketich recalled "that it seemed to change more or less around the fifties. . . . That's about the time our people started educating themselves a little more. Our boys would go out to high school and then they would start taking night courses in mining" (1982, p. 102). In a detailed account of one age cohort in another community, Joseph Illick wrote that during the early 1950s the high school in Bethlehem, Pennsylvania, was "a focal point of the city, and the students responded to that fact with enthusiasm." He also notes that the school's 
comprehensive mission meant that it was intended to serve all social and economic strata in the community (1989, pp. 117-19).

15. See Kenny (2000, pp. 226-28). Model has observed that Irish New Yorkers were overrepresented in government positions, securing occupations with higher status and pay than members of other groups with higher educational levels (1993, pp. 175-77). Others also treat the relatively low social standing of the urban Irish in this period. Nathan Glazer and Daniel Patrick Moynihan, in comparing the Irish to other immigrant ethnic groups, write that "the relevant question is not how the Irish have succeeded, but why they have not succeeded more," and they noted Oscar Handlin's observation that the movement of the Irish out of unskilled labor was "exceptionally slow" (1963, pp. 256-58, 276-82). Similarly, Ronald Baynor and Timothy Meagher note that "many, perhaps most, Irish immigrants never advanced far beyond the bottom of New York's economic hierarchy," although they suggest that succeeding generations fared much better (1996, p. 534). Finally, Linda Dowling Almeida has described the beginning stages of a restoration of Irish immigration in the immediate postwar years, involving especially large numbers of younger people. As educational expectations were considerably lower in Ireland at the time, it is possible that the arrival of teenagers in significant numbers could have depressed attendance rates in some centers of Irish population (Almeida 2001, chap. 2).

16. As a test of the relationship between ethnicity and school enrollment, I utilized data from the Integrated Public Use Microdata Samples (IPUMS) to identify enrollment rates for teenagers from various ethnic groups in 1950. I extracted a sample of individuals ages 16 or 17 living in metropolitan areas with populations greater than 100,000 . This yielded some 6,429 individuals for whom data on parental birthplace, race and school enrollment are available. The results are presented in the table below. Ethnicity for non-blacks is determined by father's place of birth. Although the group sizes are small, these data do not suggest that the Irish suffered lower enrollment rates than teens from other European ethnic groups. This lends credence to the effect of an Irishness factor, especially in central cities where such important areas of employment as government and the construction trades may have been dominated by a particular ethnic group.

$\begin{array}{lcr}\text { Ethric Group } & \text { Enrollmenl Rate (\%) } & \mathcal{N} \\ \text { Irish } & 85 & 78 \\ \text { Italian } & 74 & 210 \\ \text { Polish } & 79 & 102 \\ \text { Russian } & 89 & 94 \\ \text { Mexican } & 58 & 79 \\ \text { Black } & 68 & 673\end{array}$

\section{References}

Almeida, Linda D. Irish Immigrants in New 1ork City, 1945-1995. Bloomington: Indiana University Press, 2001.

Anderson, James D. The Education of Blacks in the South, 1860-1935. Chapel Hill: University of North Carolina Press, 1988.

Baynor, Ronald, and Timothy Meagher. The New York Irish. Baltimore: Johns Hopkins University Press, 1996. 


\section{Social Capital and Secondary Schooling}

Bodnar, John. Workers' World: Kinship, Community and Protest in an Industrial Society, 1900-1940. Baltimore: Johns Hopkins University Press, 1982.

Cohen, Miriam. Workshop to Office: Trwo Generations of Women in New 1ork City, 1900-1950. Ithaca, N.Y.: Cornell University Press, 1992.

Coleman, James. "Social Capital in the Creation of Human Capital." American Fournal of Sociology 94 (1988): 95-120.

Cook, Annabel K., and Donald M. Beck. "Metropolitan Dominance versus Decentralization in the Information Age." Social Science Quarterly 72, no. 2 (1991): 284-98.

Dorn, Sherman. Creating the Dropout: An Institutional and Social History of School Failure. Westport, Conn.: Praeger, 1996.

Duncan, Otis D., and Beverly Duncan. The Negro in Chicago: A Study of Residential Succession. Chicago: University of Chicago Press, 1957.

Fine, Lisa. Souls of the Skyscraper: Female Clerical Workers in Chicago, 1870-1930. Philadelphia: Temple University Press, 1990.

Freund, Rudolf J., and William J. Wilson. Regression Analysis: Statistical Modeling of a Response Variable. New York: Academic Press, 1998.

Fuller, Bruce. "Youth Job Structure and School Enrollment, 1890-1920." Sociology of Education 56 (1983): 145-56.

Glazer, Nathan, and Daniel P. Moynihan. Beyond the Meling Pot: The Negroes, Puerto Ricans, Jews, Italians, and Irish of New York City. Cambridge, Mass.: MT Press, 1963.

Goldin, Claudia. "America's Graduation from High School: The Evolution and Spread of Secondary Schooling in the Twentieth Century." Journal of Economic History 58, no. 2 (1998): 345-74.

Goldin, Claudia. "Egalitarianism and the Returns to Education during the Great Transformation of American Education." Symposium on the Economic Analysis of Social Behavior in Honor of Gary S. Becker. Fournal of Political Economy 107, no. 6, pt. 2 (December 1999): S65-S94.

Goldin, Claudia, and Lawrence F. Katz. "Human Capital and Social Capital: The Rise of Secondary Schooling in America, 1910-1940." Journal of Interdisciplinary History 29, no. 4 (1999): 683-723.

Greene, Margaret E., and Jerry A. Jacobs. "Urban Enrollments and the Growth of Schooling: Evidence from the U.S. 1910 Census Public Use Sample." American Fournal of Education (November 1992): 29-59.

Guest, Avery, and Stewart Tolnay. "Urban Industrial Structure and Fertility: The Case of Large American Cities." Journal of Interdisciplinary History 13, no. 3 (1983): 387-409.

Hawley, A. H., and B. Zimmer. The Metropolitan Community: Its People and Government. Beverly Hills, Calif: Sage, 1970.

Illick, Joseph E. At Liberty: The Story of a Community and a Generation, The Bethlehem, Pennsylvania High School Class of 1952. Knoxville: University of Tennessee Press, 1989.

Kaestle, Carl F., and M. A. Vinovskis. Education and Social Change in Nineteenth-Century Massachusetts. New York: Cambridge, 1980.

Katz, Michael B., and Ian E. Davey. "School Attendance and Early Industrialization in a Canadian City: A Multivariate Analysis." History of Education Quarterly 18, no. 3 (1978): 271-93.

Kenny, Kevin. The American Irish: A History. New York: Longman. 2000.

Levy, Frank. Dollars and Dreams: The Changing American Income Distribution. New York: Russell Sage, 1987.

Long, Clarence D. The Labor Force under Changing Income and Employment. Princeton, N.J.: Princeton University Press, 1958.

Model, Suzanne. "The Ethnic Niche and the Structure of Opportunity: Immigrants 
and Minorities in New York City." In The "Underclass" Debate: Views from History, edited by Michael B. Katz. Princeton, N.J.: Princeton University Press, 1993.

Morawska, Ewa. Insecure Prosperity: Small Town Fews in Industrial America, 1890-1940. Princeton, N.J.: Princeton University Press, 1996.

Olneck, Michael, and Marvin Lazerson. "The School Achievement of Immigrant Children, 1900-1930." History of Education Quarterly 14, no. 2 (1974): 155-83.

Perlmann, Joel. Ethnic Differences: Schooling and Social Structure among the Irish, Italians, fewes and Blacks in an American City, 1880-1920. New York: Cambridge University Press, 1988.

Perloff, Harvey, Edgar Dunn, Eric Lampard, and Richard Muth. Regions, Resources and Economic Growth. Baltimore: Johns Hopkins University Press, 1960.

Portes, Alejandro. "Social Capital: Its Origins and Applications in Modern Sociology." Annual Review of Sociology 24 (1998): 1-24.

Portes, Alejandro. "The Two Meanings of Social Capital." Sociological Forum 15, no. 1 (2000): 1-12.

Richardson, John G. "Variation in Date of Enactment of Compulsory School Attendance Laws: An Empirical Inquiry." Sociology of Education 53 (July 1980): 153-63.

Richardson, John G. "The American States and the Age of School Systems." American Fournal of Education 92 (August 1984): 473-502.

Rosenbaum, James E., Nancy Fishman, Alison Brett, and Patricia Meaden. "Can the Kerner Commission's Housing Strategy Improve Employment, Education, and Social Integration for Low Income Blacks?" North Carolina Law Review 71, no. 1 (1993): 519-56.

Rotberg, Robert I. "Social Capital and Political Culture in Africa, America, Australia, and Europe." In Patterns of Social Capital: Stability and Change in Historical Perspective, edited by Robert I. Rotberg. New York: Cambridge University Press, 2001.

Rumberger, Russell. "Dropping Out of High School: The Influence of Race, Sex, and Family Background." American Educational Research fournal 20, no. 2 (1983): 199-220.

Rury, John L. "Urban Structure and School-Participation: Immigrant Women in 1900." Social Science History 8 (August 1984): 219-41.

Rury, John L. "American School Enrollment in the Progressive Era: An Interpretive Inquiry." History of Education 14 (March 1985): 49-67.

Rury, John L. Education and Women's Work: Female Schooling and the Division of Labor in Urban America, 1870-1930. Albany, N.Y.: SUNY Press, 1991.

Tyree, Andrea. Reshuffling the Social Deck: From Mass Migration to the Transformation of the American Ethnic Hierarchy. New Brunswick, N.J.: Transaction Publishers, 1995.

U.S. Bureau of the Census. Current Population Reports: School Enrollment of the Civilian Population, October 1946. Washington, D.C.: Government Printing Office, 1947.

U.S. Bureau of the Census. Characteristics of the Population. Vol. 2. Washington, D.C.: Government Printing Office, 1951.

Von Eye, Alexander, and Christopher Schuster. Regression Analysis for the Social Sciences. New York: Academic Press, 1998.

Walters, Pamela B. "Sex and Institutional Differences in Labor Market Effects on the Expansion of Higher Education, 1952 to 1980." Sociology of Education 59, no. 4 (1986): 199-211.

Walters, Pamela B., and David R. James."Schooling for Some: Child Labor and School Enrollment of Black and White Children in the Early Twentieth-Century South." American Sociological Review 57 (October 1992): 635-50.

Walters, Pamela B., and Philip J. O'Connell. "The Family Economy, Work, and Educational Participation in the United States, 1890-1940." American Fournal of Sociology 59 (March 1988): 1116-52. 


\section{Social Capital and Secondary Schooling}

Wilson, William Julius. The Truly Disadvantaged: The Inner City, the Underclass, and Public Policy. Chicago: University of Chicago Press, 1987.

Wilson, William Julius. "Studying Inner City Dislocations: The Challenge of Public Agenda Research." American Sociological Review 56, no. 1 (February 1991): 1-14. 